\title{
RECUPERACIÓN DE LA NACIONALIDAD ESPAÑOLA RDGRN [11ª] 30 SEPTIEMBRE 2019 [NACIDO EN ARGENTINA]
}

\author{
RECOVERY OF THE SPANISH NATIONALITY \\ RDGRN [11ª] 30 SEPTEMBER 2019 [BORN IN ARGENTINA]
}

\author{
Marina VARgas Gómez-URrutia \\ Profesora Titular de Derecho internacional privado \\ Universidad Nacional de Educación a Distancia (UNED) \\ ORCID ID: 0000-0002-4574-341X
}

Recibido: 08.06.2021 / Aceptado: 25.06.2021

DOI: https://doi.org/10.20318/cdt.2021.6307

\begin{abstract}
Resumen: En este comentario se analiza el concepto de emigración-emigrante-hijo de emigrante a la luz de una resolución de la DGRN desestimatoria del recurso de apelación interpuesto con el auto del Consulado General de España en Buenos Aires que no inscribió el nacimiento del promotor por "recuperación de la nacionalidad española al no cumplir el requisito de la residencia legal en España establecido en el art. 26 del C. civil". La peculiaridad del supuesto radica en la pretensión del promotor de ampliar el concepto de emigrante-hijo de emigrante del art. 26 a un supuesto muy peculiar de emigración de ida y vuelta. Una ampliación de criterio que la DGRN no considera aceptable.
\end{abstract}

Palabras clave: pérdida y recuperación de la nacionalidad española, requisitos para la recuperación, no exigencia de la residencia en España a los emigrantes e hijos de emigrantes.

Abstract: Once Spanish nationality is lost, there is a possibility of recovering it. To do so, it is necessary to meet the following requirements: The interested party must be legally resident in Spain. However, this requirement shall not apply to emigrants or the children of emigrants (art. 26 Civil Code). This commentary analyzes a resolution of the DGRN on the recovery of Spanish nationality. The peculiarity of the case lies in the intention of the promoter to expand the concept of emigrant-children of emigrant of article 26 of the Civil Code to a very peculiar case of a back and forth emigration. An extension of the criterion that the DGRN does not consider acceptable.

Keywords: Spanish nationality, lost and recovering; requirements, legal resident, not apply to emigrants or the children of emigrants (art. 26 Civil Code).

Sumario: I. Supuesto sometido a examen: encuadre normativo, hechos del caso y carencias en el relato que dificultan la recta comprensión del supuesto. II. Requisitos para la recuperación de la nacionalidad española (art. 26 C.c y doctrina de la DGRN). 1. Español nacido en España que ha perdido la nacionalidad española. 2. No exigencia de la residencia legal en España: el privilegio para el emigrante e hijo de emigrante. III. Proyecto de reforma y reflexión final. 


\section{Supuesto sometido a examen: encuadre normativo, hechos del caso y carencias en el relato que dificultan la recta comprensión del supuesto.}

1. Encuadre normativo: la resolución de la DGRN ${ }^{1}$ analiza un supuesto que, quizá, podríamos considerar como supuesto tipo en la práctica interpretativa del órgano director frente a solicitudes de recuperación de la nacionalidad española y la no exigencia de la residencia en España. Como es sabido, uno de los requisitos para la recuperación de la nacionalidad española es la residencia legal en España; ahora bien, no se exige para los emigrantes e hijos de emigrantes (art. 26 C.c). De donde, el concepto de emigrante o hijo de emigrante resulta clave para saber si, en la especie, el promotor era emigrante o hijo de emigrante. La exposición de los hechos y circunstancias del caso recogidos en la RDGRN son parcos, cuasi lacónicos y repetitivos pues reitera los hechos en los fundamentos de derecho. Aun a riesgo de equivocarnos (y dado que la consulta del expediente no es posible) habremos de plantear algunas hipótesis de trabajo relacionadas con las vías de acceso a la nacionalidad española tanto del promotor como de su progenitora así como la vinculación de ambos con España, en nuestra opinión, elementos claves para un correcto planteamiento del problema y su consecuente análisis.

2. Hechos del caso: en la especie se trataba de un ciudadano argentino que promueve ante el Consulado General de España en Buenos Aires la recuperación de la nacionalidad española con solicitud de no exigencia ${ }^{2}$ del requisito de la residencia en España por ser emigrante o hijo de emigrante. Como datos fácticos relevantes figuran: (1) fecha y lugar en que promueve la recuperación de la nacionalidad (octubre 2016 ante el Encargado del Registro civil del Consulado General de España en Buenos Aires; (2) fecha y lugar de nacimiento (Buenos Aires, 1992); (3) filiación (hijo de española nacida también en Argentina en el año 1962 e hija de padre español nacido en España); (4) año y lugar de inscripción del certificado de nacionalidad del promotor (2002, en el Registro civil central); (5) pérdida de la nacionalidad española por utilización exclusiva de la nacionalidad "que ostenta" (inscrita en el marginal del acta de nacimiento por resolución registral dictada por el Encargado del Registro Civil del Consulado General de España en Buenos Aires, pero no consta la fecha de esta resolución consular).

3. Carencias en el relato que dificultan la recta comprensión del supuesto. Pese a que constan los datos referidos a la fecha de nacimiento y de solicitud de la recuperación ${ }^{3}$ quedan algunas zonas menos claras. Así, de acuerdo con la resolución, son claros la fecha y lugar de nacimiento del promotor y el lugar de su residencia en el momento de la solicitud de recuperación (1992, Buenos Aires en ambos momentos); su condición de español de origen y la fecha e inscripción del certificado de nacimiento (2002, Registro Civil Central); la residencia en España de su madre durante los años 2002 a 2007; y, la pérdida de la nacionalidad española del promotor por no declarar la conservación entre los 18 y los 21 años. Consta que instó la recuperación el 21 de octubre de 2016 (es decir, ya cumplidos los 22 años). Son datos o zonas menos claras: la fecha en que la madre del promotor adquirió de la nacionalidad española y el modo en que esta la transmitió a su hijo. Dato relevante para la recuperación pues podría haber arrojado luz para una interpretación más amplia del concepto de emigración y de emigrante e hijo de emigrante del art. $26 \mathrm{C}$. civil que favoreciera la pretensión del promotor (que a él le alcanza el derecho subjetivo de la exención del requisito de residencia legal en España).

${ }^{1}$ RDGRN [11 $] 30$ septiembre 2019 [nacido en Argentina] [BIMJ, núm. 2233, septiembre 2020] - inscripción de nacimiento y recuperación nacionalidad española (nacido en Argentina), p. 155.

${ }^{2}$ Conviene no confundir la dispensa de la residencia con la no exigencia de la residencia. La dispensa de la residencia es un concepto jurídico determinado en el art. 26 del C. civil, que se aplica al extranjero que desea recuperar la nacionalidad española pero que no es emigrante ni hijo de emigrante español. La otorga el Ministro de Justica cuando concurran circunstancias excepcionales. La no exigencia de la residencia legal es un derecho subjetivo que tiene el promotor cuando concurren en él las circunstancias o requisitos establecidos en la norma. En el caso que analizamos se trata del segundo.

${ }^{3}$ Como es sabido, en materia de adquisición y pérdida de la nacionalidad española, la normativa aplicable en cada supuesto es temporal es decisiva pues para conocer si se adquirió o se perdió la nacionalidad ha de estarse a lo dispuesto en la redacción vigente de la norma en cada el momento temporal en que se produce el hecho. 
4. A primera vista, todo apunta a que la madre no es española de origen (a diferencia del hijo que, según la resolución, sí consta inscrito como español de origen); de donde cabe pensar como escenario jurídico que: (1) en el momento del nacimiento de la madre del promotor (1962) su padre ya no le transmitió la nacionalidad española (la habría perdido, quizá, por adquisición de la nacionalidad argentina); $y$, que (2) ella (la madre del promotor) o bien pudo adquirirla derivativamente por la vía de la opción del art. 20 C. civil o bien pudo recuperarla en un momento anterior al nacimiento del hijo (1992) y en todo caso, antes de la venida a España (2002).

5. Tanto en el supuesto de que la hubiera adquirido por la vía de la opción del art. 20.1 b) C. civil como en el caso de que la hubiera recuperado antes de venir a España en 2002, no parece que haya dudas de que la madre del promotor es hija de un español emigrante. Esta condición de emigrante e hijo de emigrante no se traslada, sin embargo, a los nietos (aquí, en el caso, es el promotor) a los efectos del privilegio jurídico de la no exigencia de la residencia legal en España para la recuperación. De la resolución se desprende que el promotor parece entenderlo de igual modo y por ello insta a la DGRN una interpretación más amplia del concepto de emigración de manera que cubra el supuesto que a él le afecta: ha perdido la nacionalidad española de origen por no haber realizado la declaración de conservación en tiempo; para recuperar ha de venir a residir a España porque "no es hijo de emigrante" en los términos que interpreta la DGRN; ahora bien, como la madre del promotor había venido a España residiendo varios años hasta que volvió a Argentina (país de nacimiento y de nacionalidad), entiende el promotor que existe una emigración de su madre y que por eso debe ser considerado como hijo de emigrante. ¿Hay una verdadera emigración? ¿Qué línea de interpretación sigue el centro directivo?

6. La DGRN es rotunda en su rechazo a la pretensión del promotor. Descarta una interpretación más flexible del concepto (aunque afirma que emigración es un concepto amplio) y sostiene una interpretación literal $\left(\mathrm{FJ}^{\circ}\right.$ ) basada en los tres elementos o criterios sobre los que se construyen el concepto en esta sede normativas: debe tratarse (solo) de un español nacido en España, que traslada su domicilio al extranjero y adquiere otra nacionalidad. Ni los motivos para emigrar ni las razones por las que se adquiere otra nacionalidad son relevantes para la construcción del concepto de emigración. Sobre esta base la DGRN declara que no ve justificación alguna para cambiar de criterio a la luz de la redacción vigente del precepto (dada por Ley 36/2002, de 8 de octubre) y a las anteriores redacciones (dada por Ley 51/1982, de 13 de julio y Ley 18/1990, de 17 de diciembre más las Instrucciones sobre nacionalidad de 16 de mayo de 1983 y de 20 de marzo de 1991$)^{4}$.

7. ¿Es congruente esta interpretación? ¿Es adecuada a los tiempos? ¿Cabría flexibilizar la interpretación del concepto "emigración" a los efectos del art. 26 C.c. en los términos pretendidos por el promotor? ¿Con qué alcance? Para intentar dar respuesta a estas interrogantes, analizaremos los requisitos para

\footnotetext{
${ }^{4}$ Ley 36/2002, de 8 de octubre, de modificación del Código Civil en materia de nacionalidad. Y comentario de A. ALVAREZ Rodríguez, "Principios inspiradores y objetivos de la nueva reforma del Derecho español de la nacionalidad: las principales novedades de la Ley 36/2002, de 8 de octubre", Revista de Derecho migratorio y extranjería, año 2002, vol. 1, pp. 47-86. Ley 51/1982, de 13 de julio, de modificación de los artículos 17 a 26 del C. civil; Ley 18/1990, de 17 de diciembre, de modificación del Código civil en materia de nacionalidad; Instrucción de 16 de mayo de 1983; Instrucción de 20 de marzo de 1991. Repárese que esta última Instrucción se aclara el alcance del nuevo régimen y consecuentemente se declara "la desaparición del régimen especial establecido en la disposición transitoria de la Ley 15/1982, de 13 de julio de modo que (Apartado VII): “(...) todos aquellos que hayan sido alguna vez españoles y hayan perdido esta nacionalidad solo pueden recuperarla, en principio, cumpliendo los requisitos establecidos por el artículo 26 del Código. Nótese, por otra parte, que la pérdida se habrá producido, en su caso, según la legislación vigente en cada momento anterior por aplicación de la disposición transitoria primera de la ley de 1990. En cuanto al requisito de residencia legal en españa, según el artículo 26-1-a, "cuando se trate de emigrantes o hijos de emigrantes, este requisito podrá ser dispensado por el gobierno" y “en los demás casos, la dispensa solo será posible si concurren circunstancias especiales". De este precepto se deduce claramente, y así lo resalta el Preámbulo de la Ley, que quiere darse un trato de favor a los emigrantes y a sus hijos, es decir, también en contra de la doctrina oficial sentada bajo la ley anterior (cfr. Instrucción de 16 de mayo de 1983, epígrafe iii, a), a los hijos de emigrantes cuando tales hijos hayan nacido en el extranjero. Además, solo se exige hoy el hecho físico de la emigración y no que la adquisición de la nacionalidad extranjera haya sido una consecuencia de aquella" (el subrayado es nuestro).
} 
la recuperación de la nacionalidad española a la luz de lo dispuesto en el artículo 26 del Código civil y la doctrina de la DGRN y veremos cómo se proyectan en el caso de la resolución objeto de este comentario.

\section{Requisitos para la recuperación de la nacionalidad española (art. 26 Cc. y doctrina de la DGRN).}

\section{Español nacido en España que ha perdido la nacionalidad española.}

8. Tres requisitos son exigidos por el Código civil para la recuperación de la nacionalidad española. El primero referido a la propia condición de español del solicitante, el segundo a la pérdida de la nacionalidad española y el tercero a la residencia legal en España y su posible exención.

9. Sobre el primero, la doctrina de la DGRN es clara y constante ${ }^{5}$ en el sentido de que no se puede recuperar lo que nunca se tuvo. Quien desee recuperar la nacionalidad ha de ser "español de iure". ¿Significa esto que el solicitante ha de probar su nacionalidad española? Y, en su caso, ¿cómo se prueba?

10. En realidad se trata de tener en cuenta los criterios de aplicación temporal del derecho de la nacionalidad ${ }^{6}$. Saber si la persona es o no es española lo determinan las normas vigentes en el momento del nacimiento y ello con independencia de la documentación que exhiba el promotor. Como ejemplo clásico de no atribución de la nacionalidad es el caso de hijos de madre española casada con extranjero y nacidos antes de la reforma de 1982. Siendo que la mujer casada seguía la condición y la nacionalidad del marido (art. 22 C.c., redacción originaria -RD 24/07/1889) y los hijos la nacionalidad del padre, resultaba que el criterio del iure sanguinis no alcanzaba a la filiación materna. Así, entre otras, la RDGRN $5^{\text {a de }} 3$ marzo 2009: nacida en España en 1953, hija de francés y española, no es española pues sigue la nacionalidad francesa del padre ${ }^{8}$.

11. El segundo de los requisitos es la pérdida de la nacionalidad española. Es muy frecuente que muchos españoles nacidos en el extranjero y que tienen atribuida desde el nacimiento otra nacionalidad (normalmente porque en el país de nacimiento el ius soli es el criterio principal de atribución), no son conscientes de que pueden perder la nacionalidad ex lege. El artículo $24 \mathrm{C}$. civil, en su redacción dada por la Ley 36/2002, contempla cuatro supuestos o situaciones que dan lugar a la pérdida ${ }^{9}$. En el caso de la resolución que se comenta consta anotada en el certificado español de nacimiento la inscripción de pérdida de la nacionalidad española de origen por utilización exclusiva de la nacionalidad que ostenta, en virtud de resolución registral dictada por el Encargado del Registro civil del Consulado General de España en Buenos Aires (FJ III).

\footnotetext{
${ }^{5}$ Véanse las referencias a las resoluciones de la DGRN recopiladas por A. AlvarEZ RoDRíGUEZ, Nociones básicas del Registro Civil y problemas frecuentes en materia de nacionalidad, Ediciones GPS, Madrid, 2015, p. 271; y las de J. CARRASCOSA GonzÁlez, Derecho español de la nacionalidad, Comares (Granada), 2011, pp. 228-231. Para consulta de las resoluciones de la Dirección General en versión electrónica (disponibles desde 2009) véase la publicación oficial del Ministerio de Justicia (BIMJ) disponible en: Boletín del Ministerio de Justicia.

${ }^{6}$ En este sentido, A. Álvarez Rodríguez, Nociones básicas, op. cit., p. 275 ss; J. Carrascosa González, Derecho español de la nacionalidad, op. cit, p. 228: J.M. Espinar Vicente / M. Guzmán Peces, La nacionalidad y la extranjería en el sistema jurídico español, Dykinson, Madrid, 2019.

${ }^{7}$ Art. 17 Segundo C. civil, en redacción dada por Ley de 15 de julio de 1954: Son españoles: los hijos de madre española aunque el padre sea extranjero cuando no sigan la nacionalidad del padre.

${ }^{8}$ Aplicación del apartado I de la Instrucción de 16 de mayo de 1983 (...) Puesto que no existe disposición transitoria en la nueva ley (...) es preciso entender que esta novedad no puede tener efecto retroactivo (cfr. artículo 2, $33^{\circ}$ del Código Civil, (---) y por lo tanto, que únicamente podrán ser considerado, por ese solo título, españoles de origen los hijos de madre española nacidos después de la entrada en vigor de la Ley de 13 de julio de 1982.

9 Sobre la pérdida, entre otros, véase: A. Álvarez Rodríguez, "Derecho de la nacionalidad en España", en Normativas de Nacionalidad en Derecho comparado (R. Rueda Valdivia / A. Lara Aguado, Dirs.), Tirant lo Blanch, 2020, p. 407-444, esp. p. 431-435 M. Vargas Gómez-URrutia, "La nacionalidad, española", en Lecciones de Derecho internacional privado, Tirant lo Blanch, pp. 188-220, esp. pp. 209-212.
} 
12. En efecto, a tenor de la resolución consular, el supuesto se encuadra en el párrafo 3 del art. 24 C. civil: "perderán en todo caso la nacionalidad española los que habiendo nacido y residiendo en el extranjero ostentan la nacionalidad española por ser hijos de padre o madre españoles, también nacidos en extranjero, cuando las leyes del país donde residen les atribuyan la nacionalidad de esta. Esta pérdida podrá evitarse si declaran su voluntad de conservarla ente el Encargado del Registro civil en el plazo de 3 años a contar desde su mayoría de edad o emancipación" ${ }^{10}$. La pérdida se produce ex lege si no se realiza la declaración.

13. La DGRN, en su Instrucción de 20 de marzo de 1991, ha indicado que "por el carácter taxativo de las causas de pérdida, que no pueden ser objeto de interpretación extensiva (...), tener la documentación española, haber otorgado algún documento público, haber comparecido ante el Consulado como español, y otras conductas semejantes, serán un índice de que el interesado no habrá podido incurrir en pérdida de la nacionalidad española". La DGRN en diversas resoluciones afirma que (...) "Los requisitos exigidos por el artículo 241 del Código civil para que se produzca la pérdida de la nacionalidad española, esto es, utilización exclusiva de la otra nacionalidad distinta de la española, emancipación y residencia habitual en el extranjero durante los tres años posteriores, han de concurrir acumulativamente" (entre otras, RDGRN de 2 de junio de 2008).

14. Sobre este extremo, el Tribunal Supremo ha resuelto una duda acerca del alcance de la solicitud de declaración de voluntad. A saber, si a los efectos del art. 24.3 C. civil bastaba por ejemplo la solicitud de renovación del pasaporte en el Consulado español y antes de que transcurrieran los 3 años. La Sala se pronunció a favor de una interpretación más flexible. Y así, ni se requiere de una declaración formal sujeta a forma solemne ni hay inconveniente en admitir que esa voluntad se manifieste de forma indirecta por actos concluyentes, por ejemplo, la personación del interesado ante el consulado para renovar el pasaporte (STS 19/12/201911). Resulta de interés resaltar la comprensión que hace el Tribunal Supremo del espíritu de la norma (art. 24.3 C.c) y su relación con la norma de recuperación (art. 26 C.c) indicando referencias al debate doctrinal respecto de redacciones precedentes (FJ Segundo 4.2).

15. Y así, tras resaltar que la exposición de motivos de la Ley no hace referencia a su finalidad, sin embargo, la doctrina es unánime en su entendimiento pues se dirige a evitar la perpetuación de estirpes indefinidas de descendientes de españoles en el extranjero, de modo que continúen siendo españoles aunque no mantengan ninguna vinculación con España, incluso sin saber que son españoles. Otro elemento de reflexión y crítica que menciona el Alto Tribunal se refiere a los nacionales de países iberoamericanos. La doctrina ha señalado que se daba la situación paradójica (antes de la reforma del 2002) de que "el no emancipado nunca incurría en causa de pérdida y al llegar la emancipación, al no regir la doctrina del asentimiento voluntario, solo su renuncia expresa provocaba la pérdida, y los hijos y sucesivos descendientes, mientras no sobreviniera su renuncia, serían igualmente españoles". En este sentido, se propugnó resolver la paradoja retornando a la redacción de la pérdida dada por la Ley de 15 de julio de 1954: "Los que habiendo nacido y residiendo en el extranjero ostenten la nacionalidad española por ser hijos de padre

${ }^{10}$ Sobre las normas de nacionalidad en Argentina, véase el estudio de G. Pons Vitadinni, en Normativas de Nacionalidad en Derecho comparado (R. Rueda Valdivia / A. LaRa Aguado, Dirs.), Tirant lo Blanch, 2020, p. 95-109, esp. p. 97 sobre la adquisición por ius soli, como criterio principal de atribución y p. 103 sobre la pérdida. En la actualidad la única causa de pérdida es la adquisición en fraude previa declaración de nulidad. Se admiten las situaciones de plurinacionalidad en virtud de convenio (con España el firmado el 14 de abril de 1969). En consecuencia, a diferencia del Derecho español, la nacionalidad argentina no se pierde por la adquisición de una nacionalidad extranjera y, en este sentido, se ha pronunciado la Suprema Corte de Justicia de la Nación en Expediente no 3819/04, de 10 de abril de 2007 (op.cit., p.103).

11 STS 4072/2019 - ECLI: ES:TS:2019:4072. Sala de lo Civil. Ponente: M. Ángeles Parra Lucán. En la especie, la Sala resuelve un recurso de casación por dos motivos: infracción de los arts. 14 y 11.2 CE por vulneración del derecho a la igualdad, al haberse decretado la pérdida de la nacionalidad de origen de la recurrente en contra de lo preceptuado en el art. 11.2 CE, que establece que ningún español de origen podrá ser privado de su nacionalidad. El segundo motivo denuncia la vulneración de los arts. 14 y 25.1 CE, 24.3 CC y 226 del Reglamento del Registro Civil y del principio de legalidad, por considerar que la sentencia recurrida impone exigencias "extra legem", al requerir que la declaración de conservación de la nacionalidad española sea explícita (FJ Segundo). 
o madre españoles, también nacidos en el extranjero, aunque las leyes del país donde residan les atribuyan la nacionalidad del mismo, no perderán la española si declaran expresamente su voluntad de conservarla ante el Agente diplomático o consular español o, en su defecto, en documento debidamente autenticado dirigido al Ministerio de Asuntos Exteriores de España” (art. 26).

16. Con posterioridad, la Ley del Registro Civil de 8 de junio de 1957 introdujo en su art. 65 una disposición complementaria conforme a la cual la declaración a que se refería el art. $26 \mathrm{CC}$ solo podía hacerse dentro de un año a contar de la fecha en que la ley del país de residencia atribuyera la nacionalidad o desde la mayoría de edad o emancipación si la ley extranjera la hubiera atribuido antes. El precepto dejó de tener sentido con la redacción del art. 26 tras la reforma del 2002.

17. Concluye la Sala que al introducir en 2002 una norma equivalente a la del art. 26 C. civil en la redacción de 1954, "se quiso establecer un cauce que permitiera cortar la perpetuación indefinida de estirpes de españoles en el extranjero cuando siguen siendo españoles a pesar de que no mantengan la menor vinculación con España. Se hace exigiendo a los nietos de emigrados españoles, segunda generación nacida en el país de acogida, una declaración de voluntad dentro de cierto plazo para no perder la a nacionalidad española. La pérdida de la nacionalidad se produce ex lege si no se realiza esa declaración".

\section{Residencia legal en España y su no exigencia: privilegio para el emigrante e hijo de emigrante.}

18. El tercer requisito para la recuperación es la residencia legal en España y su posible exención, que afecta a los emigrante e hijos de emigrantes. La naturaleza de la residencia ha de ser legal y por ende habrá de estarse a lo dispuesto en las normas sobre entrada, permanencia y residencia en España del derecho de extranjería (bien sean las normas del régimen general de la LO 4/2000 y RD 577/2011 o las del régimen aplicable a los familiares de comunitarios en el RD 240/2007). El artículo 26 del C. civil no establece un periodo de residencia previo para iniciar el expediente; cabe afirmar, pues, que una vez que el interesado ha obtenido la documentación acreditativa de su autorización de residencia en España podrá solicitar la recuperación ${ }^{12}$.

19. En relación al concepto de emigrante, en la resolución que se comenta la DGRN entendió que (...) ni el interesado ni su madre pueden ser considerados emigrantes, ya que ambos nacieron en Buenos Aires (énfasis nuestro). Varias consideraciones pueden hacerse a la luz de la doctrina de la DGRN y los datos del caso:

1) ¿El concepto de hijo de inmigrante alcanza a la madre del promotor? La resolución sostiene que la madre del promotor no es emigrante porque no ha nacido en España. Esta afirmación llama la atención en una primera lectura si tenemos en cuenta que el privilegio o trato jurídico más beneficioso (no residir en España para solicitar la recuperación) se extiende a los hijos del emigrante.

2) Ahora bien, la negativa de la DGRN adquiere sentido en el contexto de la solicitud del promotor que sostiene que la "primera" emigrante es la madre y no el abuelo. Se trataría pues de saber si el hecho del retorno a España de la hija de emigrante español nacida en el extranjero es restaurativo de la emigración. Para el promotor sí lo es y por ello entiende que a él le alcanza el régimen jurídico privilegiado. Aunque en la resolución nada se argumenta (o al menos no se recoge) en pro de una interpretación "nueva" que sustente el cambio de criterio del concepto emigración/emigrante español, lo cierto es que el caso no es inusual y puede que empiece a darse cada vez más. Pero, es igualmente cierto que sin una adecuada fundamentación difícilmente podrá la DGRN ampliar el concepto del emigrante española para el cual está pensado la norma de recuperación.

${ }^{12}$ Por referencia a este supuesto véanse las resoluciones DGRN citadas por J. CARRASCOSA GonZÁlez, op. cit, p. 231 de: 19 septiembre 1988,10 febrero 1989, 27 octubre $1995\left(1^{\text {a }}\right)$ y 16 julio 2005. 
20. En efecto, recordemos que, aunque la DGRN otorga un sentido amplio al concepto de emigración al mismo tiempo lo restringe, pues la idea de emigración que subyace en el precepto y en la doctrina del centro directivo se basa en una idea de emigración propia del siglo XX y en una idea de recuperación que privilegiara a los hijos de españoles nacidos en el extranjero (pero no a los nietos, como muy bien se apunta en la STS de 19/12/2109). Para ser considerado emigrante (a los efectos de la recuperación), la persona ha de nacer en España y ser español, ha de moverse a otro país y ha de fijar su residencia en ese país, ha de haber adquirido la nacionalidad de este país y ha de haber perdido la nacionalidad española, sin que los motivos del traslado sean relevantes para el concepto ${ }^{13}$. ¿Tiene cabida esa "otra emigración" que pretende el promotor en el supuesto de hecho del art. 26 del C. civil? ¿O, bastaría con modificar el art. 24.3 del C. civil?

\section{Proyecto de reforma y reflexión final.}

21. A nuestro modo de ver, no tiene cabida y sí bastaría con modificar el supuesto del art. 24.3 del C. civil. Cierto es que hoy en día podemos ver una "nueva" emigración de ida y vuelta que podría darse cuando, como en el supuesto, el hijo del emigrante español que ha nacido en el extranjero y siendo ya español viene a España, reside un tiempo y retorna a su país de nacimiento y nacionalidad. Sus descendientes, también nacidos fuera de España, han podido adquirir la nacionalidad española sin necesidad de residir en España gracias a la vía de la opción del art. 20 del C. civil y, sobre todo, a la privilegiada opción de la Disposición adicional séptima de la llamada Ley de Memoria Histórica ${ }^{14}$, siendo que estas terceras generaciones pueden perder ex lege la nacionalidad si no hacen la declaración de conservación del art. 24.3 del C. civil

22. ¿Qué camino les queda para la recuperación? El que marca el art. 26 del C. civil, pero no pueden acogerse al privilegio de la no exigencia de la residencia en España porque las terceras generaciones (los nietos del emigrante español nacido en España) no están contempladas en la misma. Una interpretación del concepto de emigrante como la que pretende el promotor es, en nuestra opinión, demasiado forzada y no encaja en el precepto, por mucho que la emigración de hoy en día y, sobre todo, el perfil del emigrante español nada tenga que ver con el que inspiró la redacción de la norma de pérdida y recuperación (en la Ley de 1954, según hemos visto). Pero otros caminos son posibles.

23. Cabría, en el caso concernido, acudir a la dispensa ante el Ministro de Justicia, también al amparo del art. 26 del C. civil, alegando como circunstancias excepcionales las que la Orden del Ministerio de Justicia de 11 de julio de 1991 sugiere $^{15}$. Por ejemplo, la ausencia de antecedentes penales, la adaptación a la cultura española y el conocimiento del idioma, etc. Pero, sobre todo, el hecho de que la madre retornó a España y residió varios años y el dato de que el promotor ha sido español de origen y ha intentado conservar la nacionalidad española haciendo la declaración, aunque fuera de plazo. En suma, mostrar una vinculación específica con España y un deseo de querer seguir siendo español.

${ }^{13}$ Del examen de las resoluciones de la DGRN se observa que el centro directivo sí recoge los motivos del traslado siendo estos muy variados: laborales, políticos, militares, familiares (matrimonio) e incluso ha equiparado al concepto de emigración - emigrante y por tanto con derecho a recuperar la nacionalidad española de modo privilegiado (sin trasladar la residencia a España) al supuesto de pérdida de la nacionalidad española por adopción y adquisición de la nacionalidad de los padres adoptivos. J. Carrascosa GonzÁlez, op. cit, p. 232.

${ }^{14}$ Ley 52/2007, de 26 de diciembre, por la que se reconocen y amplían derechos y se establecen medidas en favor de quienes padecieron persecución o violencia durante la guerra civil y la dictadura. Disposición adicional séptima. Adquisición de la nacionalidad española. 1. Las personas cuyo padre o madre hubiese sido originariamente español podrán optar a la nacionalidad española de origen si formalizan su declaración en el plazo de dos años desde la entrada en vigor de la presente Disposición adicional. Dicho plazo podrá ser prorrogado por acuerdo de Consejo de Ministros hasta el límite de un año. 2. Este derecho también se reconocerá a los nietos de quienes perdieron o tuvieron que renunciar a la nacionalidad española como consecuencia del exilio. Y la Instrucción de la DGRN de 4/11/2008 sobre derecho de opción a la nacionalidad española según la DA7a de la Ley 52/2007.

${ }^{15}$ Orden de 11 de julio de 1991 sobre tramitación de expedientes de dispensa del requisito de residencia en España. 
24. Ahora bien, quizá la vía normativa más eficaz, y la que probablemente termine por adoptarse, es la modificación del artículo 24.3 del Código civil. La Proposición de Ley en materia de concesión de la nacionalidad española a los descendientes nacidos en el extranjero de progenitores españoles, presentada por el Grupo Parlamentario Izquierda Confederal (Adelante Andalucía, Més per Mallorca, Más Madrid, Compromís, Geroa Bai y Catalunya en Comú Podem ${ }^{16}$ ya lo contempla.

Su Exposición de Motivos es elocuente al respecto:

"De hecho, siguen existiendo diversos supuestos que exigen una reparación que, con el actual marco normativo, no se ha producido. Así, es preciso ofrecer una salida a las siguientes realidades:

(...) 4. Los nietos y nietas de nacionales españoles que, habiendo ostentado la nacionalidad, la han perdido por no ratificar su deseo de conservarla al cumplir su mayoría de edad. Algunos de ellos pudieron recuperar su nacionalidad y otros no debido a la falta de una Instrucción específica para este supuesto en particular que dejó esa posibilidad a la interpretación de cada registro consular".

Y, en este sentido, propone la modificación del art. 24.3 del C. civil que quedaría redactado del modo siguiente:

"Los que habiendo nacido y residiendo en el extranjero ostenten la nacionalidad española por ser hijos de padre o madre españoles, también nacidos en el extranjero, cuando las leyes del país donde residan les atribuyan la nacionalidad del mismo, solo perderán la nacionalidad española si declaran su renuncia expresa ante autoridades del Registro Civil consular correspondiente a su domicilio de residencia, cumpliendo los requisitos previstos en el párrafo anterior".

25. $\mathrm{Y}$ es que, en ocasiones, conviene recordar que el sentimiento de pertenencia de los españoles que conformaron aquellas convulsas migraciones del siglo XX, la de los abuelos que guiaron a sus hijos y a sus nietos hacia "el sueño de la madre patria", se ha mantenido en muchos hogares (no solo de la América española). El saber que no se les permitía regresar a España quizá haya hecho a aquellas generaciones más conscientes del "sueño" del retorno. Pero hoy, "el sueño" de sus nietos no guarda ninguna relación con la nueva aventura donde el retorno se anuda a la exigencia de la residencia legal con los condicionantes económicos y políticos de las leyes de extranjería. A veces, con ingenua ligereza asumimos que el mundo ha cambiado, pensamos en que hemos superado las consecuencias de aquella emigración española del pasado siglo. No es tan evidente, no al menos en materia de nacionalidad. Visto ahora, esta resolución es un buen ejemplo para meditar sobre la incomprensible dilación parlamentaria de la tramitación de la reforma del del C. civil sobre la pérdida/recuperación de la nacionalidad española a los descendientes nacidos en el extranjero de progenitores españoles también nacidos en el extranjero.

${ }_{16}$ Proposición de Ley en materia de concesión de la nacionalidad española a los descendientes nacidos en el extranjero de progenitores españoles (BOCG, Senado - 20/01/2020). Al no haberse presentado proposiciones de ley alternativas, el texto pasó al trámite de inclusión en alguna sesión plenaria para su toma en consideración (BOCG, Senado - 20/02/2020). Situación actual: pendiente de toma en consideración (consulta de 07/06/2021). 